\title{
RADIATION INDUCED CHRONIC GI INJURY - OUR INSTITUTE EXPERIENCE
}

\section{Boojala Avinash Reddy*}

\section{S Kavitha}

\section{A Aravind}

\section{ABSTRACT}

Background: Early and late GIgastrointestinal injury may occur following irradiation of thoracic abdominal, and pelvic malignancies, which limits radiation doses that can be delivered as well as causing significant morbidity requiring intervention. We analysed the injury with respect to spectrum of injury, severity, morbidity and treatment required.

Methods: Patients with chronic radiation injury defined as illness presenting after 3 months of radiation treatment were included in the study. The study period was two years.

Results: Total number of patients studied were 53. Stricture esophagus was the most common injury, others being radiation proctocolitis, stricture cricopharynx, partial gastric outlet obstruction, radiation duodenitis, small bowel obstruction, jejunal ulceration, colovesical fistula and anal canal stricture. Endoscopic treatment was required in $75 \%$ patients. Surgery was required in $9.4 \%$ patients.

Conclusion: Chronic radiation injury causes significant morbidity requiring prolonged treatment and hospitalization. Dose and duration of radiation had direct relation to the severity of injury. Concurrent chemotherapy had no effect on severity of chronic GI injury. Majority of reported forms of chronic injury required repeated endoscopic treatment. Response to treatment was not related to endoscopic or clinical severity of injury or dose of radiation given.

\section{KEYWORDS : radiation, GI injury, strictures, proctocolitis, endoscopy}

\section{INTRODUCTION}

Early and late GI injury may occur following irradiation of thoracic, abdominal and pelvic malignancies, which limits radiation doses that can be delivered as well as causing significant morbidity requiring intervention ${ }^{(1)}$. Our study aimed to analyse radiation induced chronic GI injury with respect to spectrum of injury, severity, morbidity and treatment required.

\section{MATERIALS AND METHODS:}

All patients presenting to Department of Digestive Health and Diseases, Kilpauk medical college, Chennai, with chronic radiation injury, defined as illness presenting after 3 months of radiation treatment were included in the study. Study period was two years.

Parameters analysed-Primary diagnosis, Dose and duration of radiation, Concurrent chemotherapy if given, radiation injury caused, severity of injury, Time of presentation of injury, endoscopic findings and the treatment required.

Exclusion criteria: Patients who underwent surgery prior to radiotherapy, patients with recurrent malignancy, patients with unknown primary malignancy,

RESULTS: Total number of patients studied were 53. Most common primary disease was carcinoma esophagus in men and was carcinoma cervix in women. Stricture esophagus was the most common injury, others being radiation proctocolitis, radiation proctitis, stricture cricopharynx, partial gastric outlet obstruction, radiation duodenitis, small bowel obstruction, jejunal ulceration, colovesical fistula and anal canal stricture. Prolonged hospitalization(>2weeks) was required in 8 patients (15\%). Endoscopic treatment was required in 40 patients $(75.5 \%)$. Surgery was required in 5 patients $(9.4 \%)$.

\begin{tabular}{|l|c|}
\hline GI INJURY & $\boldsymbol{n}$ \\
\hline Stricure esophagus & 29 \\
\hline Radiation proctocolitis & 10 \\
\hline Radiation proctitis only & 4 \\
\hline
\end{tabular}

\begin{tabular}{|l|l|}
\hline Stricture cricopharynx & 3 \\
\hline Gastric outlet obstruction & l \\
\hline Radiation Duodenitis & 1 \\
\hline Jejunal Ulceration & 1 \\
\hline Small bowel obstruction & 1 \\
\hline Colovesical fistula & 1 \\
\hline Anal canal Stricture & 2 \\
\hline Total & 53 \\
\hline
\end{tabular}

Stricture esophagus:

Mean duration of presentation - 1 year

Mean dose of radiation - $50 \mathrm{~Gy}$

Most common symptom-Dysphagia

Duration of radiation related to grade of dysphagia.

All patients required multiple sittings of endoscopic dilatation of the strictures.

Radiation proctocolitis:

Mean duration of presentation -9 months

Most common cause-Carcinoma cervix

Other causes - Sarcoma, Ca prostate

All pts had bleeding PR

All pts had anemia at presentation.

4 out of 14 pts responded to conservative treatment with sucralfate enema and rectal suspension and blood transfusion as required.

10 out of 14 required endoscopic treatment with $\mathrm{APC}$ (Argon Plasma Coagulation) or formalin therapy.

Stricture Cricopharynx- 2 of 3 required repeated endoscopic dilatations. 1 of 3 required FJ.

Partial GOO-primary was lymphoma. Required surgery. Radiation duodenitis- presented with upper GI bleed and abdominal pain. Duodenal biopsy was diagnostic. Subsided spontaneously. 
Small bowel obstruction- Primary lesion was lymphoma. Presented at 3 months of radiation. Resection and anastomosis was required.

Jejunal ulceration- Primary lesion was lymphoma. Presented with brisk hematochezia and anemia. Required resection and anastomosis.

Colovesical fistula- Primary lesion was Ca cervix. Presented with urosepsis. Required intensive care and surgery.

Anal canal Stricture-Primary lesion was Ca prostate. Required surgery.

\section{DISCUSSION}

A variety of symptoms and signs can be seen following radiation treatment which constitute the syndrome of radiation induced GI injury. Altered physiology manifests in the form of increased stool frequency, decreased bile acid and vitamin B12 absorption, increased fecal fat excretion, lactose malabsorption, rapid small-intestinal and whole-gut transit ${ }^{(2)}$. Although most of these changes improve with time, at 1 to 2 years after the completion of irradiation, at least 1 parameter of gastrointestinal function was abnormal many patients.

In a rat model changes in dose-rate had profound effects on the intensity of the inflammatory response elicited by abdominal irradiation, with HDR $(180 \mathrm{~Gy} / \mathrm{h})$ inducing a significantly higher recruitment of rolling, adherent and emigrating leukocytes than irradiation with an equal total dose at a lower dose-rate of $59 \mathrm{~Gy} / \mathrm{h}^{(1)}$.

In older studies the median duration was 6 months for radiation-induced esophageal stricture (RIES) and the risk of stricture increases substantially with a higher dose of radiation ${ }^{(3)}$. In our center, the mean duration of presentation was 1 year following radiation treatment.

The method of delivery and dose of radiation has significant impact on occurrence of adverse effects of radiation. It was conclusively proved from studies that, compared to conventional method, Conformal techniques significantly lowered the risk of late radiation-induced proctitis after radiotherapy for prostate cancer ${ }^{(4)}$.

Concurrent chemotherapy is associated with significantly increased occurence acute gastrointestinal, genitourinary, dermatological toxicities when conventional radiation therapy techniques are used ${ }^{(5)}$. Use of radio-sensitizing drugs further exacerbates the toxicity ${ }^{(6)}$.

The evidence base for current therapies is limited, but nutrition, anti-diarrhoeals, anti-inflammatories, antibiotics, probiotics, pentoxifylline, tocopherol, cholestyramine, hyperbaric oxygen, endoscopic and surgical therapies have all received attention. Given the significant morbidity and mortality associated with chronic radiation enteritis, current available preventative strategies are reviewed, including tissue-sparing radiotherapy techniques ${ }^{(7)}$.

Earlier studies demonstrated that there is a volume-effect in radiation-induced diarrhea at a dose of $50 \mathrm{~Gy}$ in 25 fractions ${ }^{(8)}$.

Acute radiation colitis is mostly self-limited, and usually, only supportive management is required. Chronic radiation colitis, a poorly predictable progressive disease, is considered as a precancerous lesion; radiation-associated malignancy has a tendency to be diagnosed at an advanced stage and to bear a dismal prognosis ${ }^{(9)}$.

The volume of rectum receiving >or $=60 \mathrm{~Gy}$ is consistently associated with the risk of Grade >or $=2$ rectal toxicity or rectal bleeding. Parameters for the Lyman-Kutcher-Burman normal tissue complication probability model from four clinical series are remarkably consistent, suggesting that high doses are predominant in determining the risk of toxicity ${ }^{(10)}$.

\section{CONCLUSION:}

Chronic radiation injury causes significant morbidity requiring prolonged treatment and hospitalization. Stricture esophagus and radiation proctocolitis are the most common chronic injuries reported. Dose and duration of radiation had direct relation to the severity of injury. Concurrent chemotherapy had no effect on severity of chronic GI injury. Majority of reported forms of chronic injury required repeated endoscopic treatment. Response to treatment was not related to endoscopic or clinical severity of injury or dose of radiation given.

\section{REFERENCES}

1. Denham JW. Influence of dose-rate on inflammatory damage and adhesion molecule expression after abdominal radiation in the rat. Int J Radiat Onco Biol Phys 2000; 47: 1460-1461 [PMID: 10939886]

2. Yeoh E, Horowitz M, Russo A, Muecke T, Robb T, Maddox A, Chatterton B. Effect of pelvic irradiation on gastrointestinal function: a prospective longitudinal study. Am J Med 1993; 95: 397-406 [PMID: 8213872

3. Choi GB, Shin JH, Song HY, Lee YS, Cho YK, Bae JI, Kim JH, Jeong YH, Park MH. Fluoroscopically guided balloon dilation for patients with esophageal stricture after radiation treatment. J Vasc Interv Radiol. 2005 Dec; 16(12):1705-10.

4. Dearnaley DP, Khoo VS, Norman AR, Meyer L, Nahum A, Tait D, Yarnold J, Horwich A. Comparison of radiation side-effects of conformal and conventional radiotherapy in prostate cancer: a randomised trial. Lancet 1999; 353: 267-272 [PMID: 9929018 DOI: 10.1016/S0140-6736(98)05180-0]

5. Meyer JJ, Willett CG, Czito BG. Emerging role of intensity modulated radiation therapy in anorectal cancer. Expert Rev Anticancer Ther 2008; 8: 585-593 [PMID: 18402525 DOI: 10.1586/14737140.8.4.585]

6. Minsky BD, Conti JA, Huang Y, Knopf K. Relationship of acute gastrointestinal toxicity and the volume of irradiated small bowel in patients receiving combined modality therapy for rectal cancer. J Clin Oncol 1995; 13: 1409-1416 [PMID: 7751886]

7. Theis VS, Sripadam R, Ramani V, Lal S. Chronic radiation enteritis. Clin Oncol (R Coll Radiol) 2010; 22: 70-83 [PMID: 19897345 DOI: 10.1016/j.clon.2009.10.003]

8. Letschert JG, Lebesque JV, de Boer RW, Hart AA, Bartelink H. Dose-volume correlation in radiation-related late small bowel complications: a clinical study. Radiother Oncol 1990; 18: 307-320 [PMID: 2244018 DOI: 10.1016/0167 8140(90)90111-9

9. Kountouras J, Zavos C. Recent advances in the management of radiation colitis. World J Gastroenterol 2008; 14: 7289-7301 [PMID: 19109862

10. Michalski JM, Gay H, Jackson A, Tucker SL, Deasy JO. Radiation dose-volume effects in radiation-induced rectal injury. Int J Radiat Oncol Biol Phys 2010; 76: S123-S129 [PMID: 20171506 DOI: 10.1016/j.jirobp.2009.03.078] 